\title{
Measurement of airflow through regulators and real time integrated monitoring
}

\author{
A. D. S. Gillies, H. W. Wu, T. I. Mayes \& A. Halim \\ University of Queensland, Brisbane, Australia
}

Published as: A.D.S. Gillies, H.W. Wu, T.I. Mayes and A. Halim, Measurement of Airflow through Regulators and Real Time Integrated Monitoring, Mine Ventilation - Proceedings North American Ninth US Mine Ventilation Symposium, De Souza (Ed), Balkema, The Netherlands, 301-308 June 2002.

\begin{abstract}
The mathematical modeling of airflow through operating mine regulators is discussed. Results are used in the development of a computerized monitoring and simulation system to provide immediate or real time data on air behavior within each branch within an underground mine ventilation network through linking of sensors to the ventilation network simulation software. Software has been developed to link real time information generated by mine ventilation monitoring sensors into the network program to undertake network simulations and allow interpretation of key system data and operational changes. The outcome of the project is an online system which can report changes in the mine ventilation system, allow causes of changes to be isolated and rectified, improve balancing of available air throughout the mine and dispense with much of the labor used for underground ventilation measurement. The main work activities involved in the research program have involved examination and modeling of regulators, software modification and considerable mine site testing and optimizing activities.
\end{abstract}

\section{INTRODUCTION}

There is a move world wide to remote or telemetric monitoring of mine atmosphere conditions. Robust, suitable and as required, intrinsically safe instruments are available for measurement of, for instance, gas concentrations, air velocity and air pressure. These are often tied to extensive mine monitoring and communication systems.

One approach to establishing air quantity through a ventilation branch is through measurement of differential pressure across an opening or regulator. Mathematical relationships are available to relate (with some qualification) pressure drop and quantity through a regulator orifice placed symmetrically in a round flow conduit. However these can, at best, only be used to approximate mine regulator behavior due to:

- The irregularity of mine regulators in shape and symmetry and their positioning in normally roughly square or rectangular mine airways,

- The construction of the mine regulator opening which may result from, for instance, the operation of louvres, a sliding door, window or curtain or placement of drop boards, and

- Uncontrolled air leakage through the regulator or adjacent bulkhead.

The study describes efforts to characterize or mathematically model regulators. It then describes how this information is used in the development of a computerized monitoring and simulation system to provide immediate or real time information on each branch within an underground mine ventilation network through linking of sensors to the ventilation network simulation software. Software has been developed to link real time information generated by mine ventilation monitoring sensors into the network program to undertake network simulations and allow interpretation of key system data and operational changes.

The outcome of the project is an online system which can report changes in the mine ventilation system, allow causes of changes to be isolated and rectified and improve balancing of available air throughout the mine, It is envisaged that in time the real time model will be an integral part of a real time mine wide planning, monitoring and control software platform and will be updated in real time along with the mine plan.

The main steps involved in examination and modeling of regulators, software modification and considerable mine site testing and optimizing activities are described.

\section{THEORY OF REGULATORS}

A regulator is an artificial resistance (in the form of shock loss) introduced into an airway to control airflow. 


\subsection{Derivation of regulator equation}

A regulator can be described as a large thin plate installed in a fluid conduit with an orifice. When a difference in pressure exists between the two sides fluid flows in the pattern shown in Figure 1. On the low pressure side the fluid issues as a converging jet in line with the centre of the orifice. The jet converges to its smallest area at a distance of about half the orifice diameter (Le Roux, 1979). This area is called the "vena contracta" $\left(A_{c}\right.$ at Fig. 1). The ratio between vena contracta and orifice area is the "coefficient of contraction", $C_{c}\left(A_{c} / A_{r}\right.$ at Fig. 1).

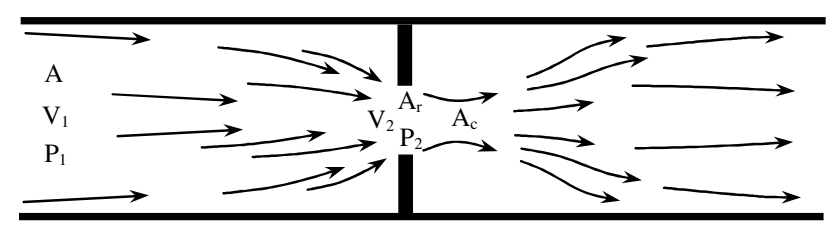

Figure 1. Airflow pattern through an orifice (after Burrows et al, 1989).

McElroy (1935) found that the $C_{c}$ value is a relation between the ratio of the orifice and airway cross sectional area, $\mathrm{N}\left(\mathrm{A}_{\mathrm{r}} / \mathrm{A}\right.$ at Fig. 1), and $\mathrm{Z}$, which is an empirical factor designated as the contraction factor, which is expressed as:

$C_{c}=\sqrt{\frac{1}{Z-Z N^{2}+N^{2}}}$

Values of $\mathrm{Z}$ vary according to the edge shape of the orifice. Since most regulators are square edged, a $\mathrm{Z}$ value of 2.5 is most commonly used in calculating $\mathrm{C}_{\mathrm{c}}$. Bernoulli's equation can be applied to both sides of the orifice as shown in Figure 1 in order to calculate the velocity and hence the airflow quantity.

A correction must be made for the contraction of the jet at the vena contracta. Since the orifice is larger than the vena contracta, orifice velocity is lower than in the vena contracta. The velocity equated based on Bernoulli's equations is the velocity at the vena contracta. Therefore, the velocity at the orifice can be obtained with the following equation:

$V_{2}=C_{c} \sqrt{\frac{2 \Delta P_{s}}{\rho}} \frac{1}{\sqrt{1-N^{2}}}$

where $\mathrm{C}_{\mathrm{c}}$ is the coefficient of contraction, as described before. Since airflow quantity through regulator $Q=V_{2} A_{r}$, it follows that:

$Q=C_{c} \sqrt{\frac{2 \Delta P_{s}}{\rho}} \frac{1}{\sqrt{1-N^{2}}} A_{r}$

where $A_{r}$ is orifice opening area in $\mathrm{m}^{2}$.

\section{FIELD TESTS OF REGULATORS}

Field tests were conducted at the University of Queensland Experimental Mine (UQEM) to verify air behavior in flow through regulators. Parameters measured were airflow quantity and pressure drop across the regulator. From pressure drop measurements, airflow quantity through the regulators can be calculated with Equation 3. Results of this calculation can be compared with measured values and the reasons for significant differences investigated.

\subsection{UQEM tests}

The UQEM regulator is the drop board type. Results of this test are summarized in Table 1 . Based on $\Delta \mathrm{P}_{\mathrm{s}}$ measured, predicted airflow quantity through the regulator, Q, was then calculated with Equation 3. Values of $Q$ were compared with the measured quantity, $\mathrm{Q}_{\mathrm{m}}$, as set down in Table 1 and Figure 2. It can be seen from both the table and figure that the measured quantity is consistently larger than predicted. There are several possible reasons as follows.

Table 1. Results of UQEM test.

\begin{tabular}{|l|c|c|c|c|}
\hline \multicolumn{1}{|c|}{ Condition } & $\begin{array}{c}\Delta \mathrm{P}_{\mathrm{s}} \\
\mathrm{Pa}\end{array}$ & $\begin{array}{c}\mathrm{Q}_{\mathrm{m}} \\
\mathrm{m}^{3} / \mathrm{s}\end{array}$ & $\begin{array}{c}\mathrm{Q} \\
\mathrm{m}^{3} / \mathrm{s}\end{array}$ & $\begin{array}{c}\text { Difference } \\
\%\end{array}$ \\
\hline Fully closed & 163 & 2.05 & 0.00 & $\mathrm{n} / \mathrm{a}$ \\
1 board off & 125 & 2.53 & 0.82 & 209.8 \\
2 boards off & 96 & 3.02 & 1.44 & 109.6 \\
3 boards off & 73 & 3.33 & 1.89 & 76.0 \\
4 boards off & 58 & 3.35 & 2.27 & 47.7 \\
5 boards off & 47 & 3.46 & 2.58 & 34.3 \\
6 boards off & 36 & 3.62 & 2.74 & 32.0 \\
7 boards off & 30 & 3.75 & 2.96 & 26.6 \\
8 boards off & 25 & 3.82 & 3.14 & 21.5 \\
9 boards off & 21 & 3.85 & 3.31 & 16.3 \\
10 boards off & 19 & 3.86 & 3.58 & 7.8 \\
11 boards off & 15 & 4.00 & 3.59 & 11.2 \\
12 boards off & 12 & 3.90 & 3.61 & 8.1 \\
13 boards off & 10 & 3.85 & 3.69 & 4.2 \\
14 boards off & 7 & 3.89 & 3.46 & 12.4 \\
\hline
\end{tabular}

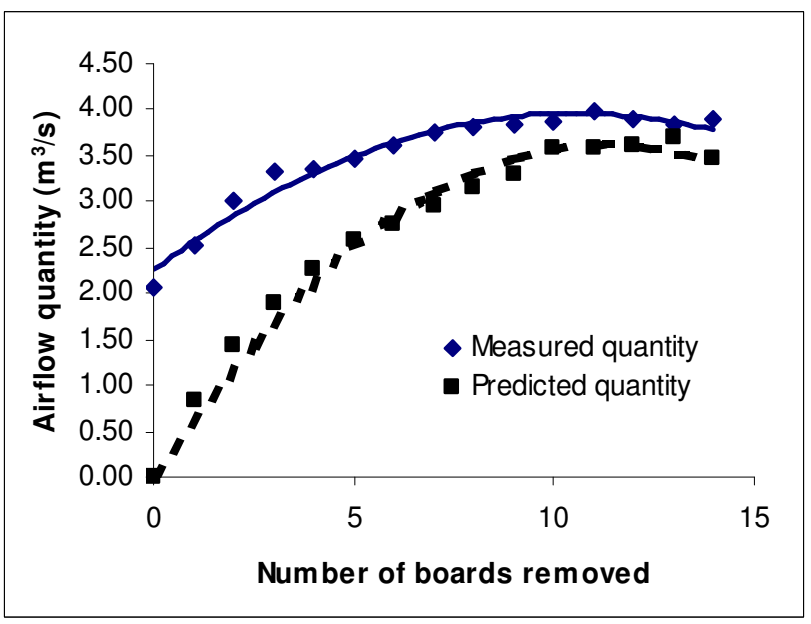

Figure 2. Comparison between measured and predicted quantity. 


\subsubsection{Error during measurement}

It is common for operator induced errors to occur during mine drift measurement especially in small cross sectional airways. The authors experienced difficulty when measuring air velocity by continuous traversing because of limited space to move freely. Also, an author's body provided a significant obstacle to the airflow.

\subsubsection{Non-symmetrical condition and shape}

Equation 3 was derived based on a circular orifice in the middle of a regulator plate. The UQEM regulator opening is located on the upper side and opening is rectangular leading to distorted air patterns.

\subsubsection{Leakage}

Leakage occurs due to the presence of gaps between boards and between the regulator frame and the airway walls. The leakage quantity depends on regulator construction and the differential pressure drop across the opening.

An approach is proposed to model the difference as air leakage since measurement error and the nonsymmetrical condition were difficult to quantify. Therefore, the airflow quantity through the regulator can be expressed as:

$Q=C_{c} \sqrt{\frac{2 \Delta P_{s}}{\rho}} \frac{1}{\sqrt{1-N^{2}}} A_{r}+Q_{l}$

where $\mathrm{Q}_{1}$ is the leakage quantity. Thus $\mathrm{Q}_{1}$ needs to be quantified. An approach to this modelling is developed.

\subsection{Relationship between airflow quantity and regulator resistance}

The regulator can be treated as a set of two parallel airways namely:

1. The regulator opening and

2. The leakage paths, that is passages through and around the regulator other than the regulator orifice itself.

This can be illustrated as in Figure 3.

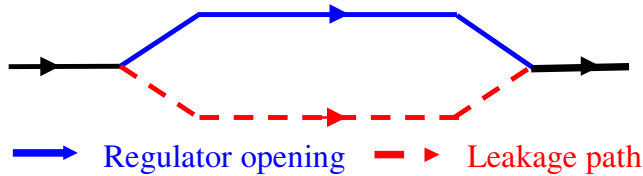

Figure 3. Airflow paths in regulator.

Therefore, the total resistance of regulator $\left(R_{t}\right)$ can be modeled to consist of the regulator opening resistance $\left(R_{0}\right)$ and the leakage path resistance $\left(R_{1}\right)$. When the regulator is in a fully closed condition, the air flows through the leakage path only.

Airflow quantity through the regulator opening is calculated using the basic square law $\left(\Delta P_{s}=R Q^{2}\right)$. Based on this equation and Equation 3, the relation- ship between $R_{0}$ and $A_{r}$ can be established as follows.

$$
\begin{aligned}
& \sqrt{\frac{\Delta P_{s}}{R_{o}}}=C_{c} \sqrt{\frac{2 \Delta P_{s}}{\rho}} \frac{1}{\sqrt{1-N^{2}}} A_{r} \\
& \sqrt{\not P_{s}} \frac{1}{\sqrt{R_{o}}}=C_{c} \sqrt{2} \sqrt{\not P_{s}} \frac{1}{\sqrt{\rho}} \frac{1}{\sqrt{1-N^{2}}} A_{r}
\end{aligned}
$$$$
\sqrt{R_{o}}=\frac{1}{C_{c} A_{r}} \sqrt{\frac{\rho\left(1-N^{2}\right)}{2}}
$$

$R_{o}=\frac{\rho\left(1-N^{2}\right)}{2 C_{c}^{2} A_{r}^{2}}$, Since $N=\frac{A_{r}}{A}$, thus

$$
\begin{aligned}
& R_{o}=\frac{\rho}{2 C_{c}^{2} A_{r}^{2}}-\frac{\rho}{2 C_{c}^{2} A^{2}} \\
& R_{o}=\frac{\rho}{2 C_{c}^{2}}\left(\frac{1}{A_{r}^{2}}-\frac{1}{A^{2}}\right)
\end{aligned}
$$

where A is the airway cross sectional area. Since this equation does not take leakage into account, the actual regulator resistance will be different to the one calculated by Equation 5. Thus actual resistance is $R_{t} . R_{t}$ is made up of $R_{o}$ and $R_{1}$ in parallel configuration and so the relationship between them can be established. Since $\mathrm{R}_{\mathrm{o}}$ has been quantified by Equation $5, R_{1}$ has to be quantified also to allow $R_{t}$ to be calculated. Thus based on the measured pressure drop, the airflow quantity through the regulator can be determined.

Table 2. UQEM regulator resistances.

\begin{tabular}{|l|c|c|c|c|}
\hline \multicolumn{1}{|c|}{ Condition } & $\begin{array}{c}\mathrm{R}_{\mathrm{t}} \\
\mathrm{Ns}^{2} / \mathrm{m}^{8}\end{array}$ & $\begin{array}{c}\mathrm{R}_{\mathrm{o}} \\
\mathrm{Ns}^{2} / \mathrm{m}^{8}\end{array}$ & $\begin{array}{c}\mathrm{R}_{1} \\
\mathrm{Ns}^{2} / \mathrm{m}^{8}\end{array}$ & $\begin{array}{c}\mathrm{A}_{\mathrm{r}} \\
\mathrm{m}^{2}\end{array}$ \\
\hline Fully closed & 38.65 & $\infty$ & 38.65 & 0 \\
1 board off & 19.46 & 186.77 & 42.43 & 0.09 \\
2 boards off & 10.56 & 46.39 & 38.61 & 0.18 \\
4 boards off & 6.58 & 20.39 & 35.31 & 0.27 \\
5 boards off & 5.17 & 11.29 & 49.52 & 0.36 \\
6 boards off & 3.93 & 7.08 & 60.21 & 0.45 \\
7 boards off & 2.75 & 4.80 & 46.76 & 0.54 \\
8 boards off & 2.13 & 3.42 & 48.32 & 0.63 \\
9 boards off & 1.71 & 2.53 & 54.71 & 0.72 \\
10 boards off & 1.42 & 1.92 & 72.25 & 0.81 \\
11 boards off & 0.94 & 1.48 & 246.09 & 0.90 \\
12 boards off & 0.79 & 0.92 & 140.23 & 1.07 \\
13 boards off & 0.68 & 0.73 & 415.53 & 1.16 \\
14 boards off & 0.46 & 0.59 & 37.87 & 1.25 \\
\hline
\end{tabular}

To do this, $R_{o}$ is first calculated using Equation 5, and then the total resistance is calculated using the square law based on the measured pressure drop and the measured airflow quantity. $\mathrm{R}_{1}$ then can be calcu- 
lated using the parallel airways resistance relationship. Table 2 shows the calculated resistance of the regulator tested at the UQEM.

To quantify $R_{1}$ a plot against regulator opening area was made, as shown in Figure 4. It was found that $R_{l}=32.734 e^{1.1631 A r}$. Therefore, the total regulator resistance, $\mathrm{R}_{\mathrm{t}}$ could be calculated from:

$\frac{1}{\sqrt{R_{t}}}=\frac{1}{\sqrt{R_{o}}}+\frac{1}{\sqrt{R_{l}}}$

$R_{o}=\frac{\rho}{2 C_{c}^{2}}\left(\frac{1}{A_{r}^{2}}-\frac{1}{A^{2}}\right)$

$R_{l}=32.734 e^{1.1631 A r}$

Therefore, the total regulator resistance, $\mathrm{R}_{\mathrm{t}}$ could be calculated. The airflow quantity was then recalculated using the square law based on the new $\mathrm{R}_{\mathrm{t}}$. Results of this was then compared with measured values, $\mathrm{Q}_{\mathrm{m}}$, as summarized in Table 3 and Figure 5.

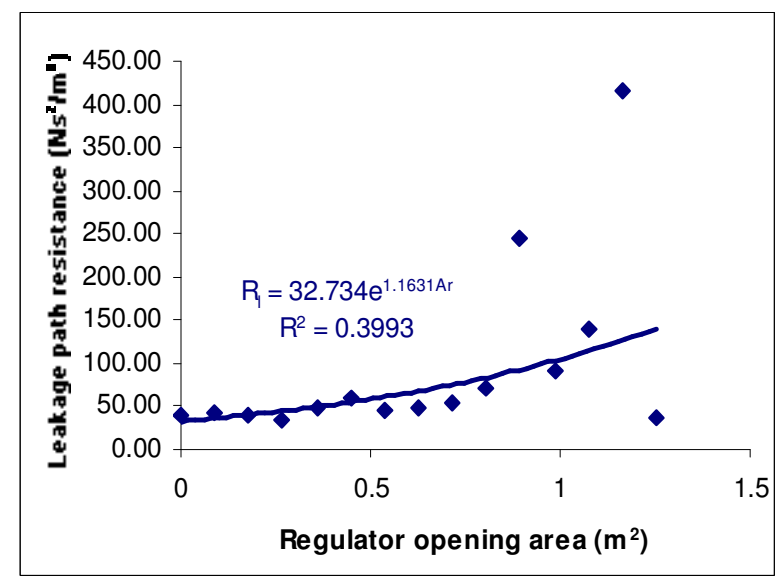

Figure 4. Quantification of resistance for leakage paths.

Table 3. Comparison between measured and new predicted quantity.

\begin{tabular}{|l|c|c|c|c|}
\hline \multicolumn{1}{|c|}{ Condition } & $\begin{array}{c}\mathrm{Q}_{\mathrm{m}} \\
\mathrm{m}^{3} / \mathrm{s}\end{array}$ & $\begin{array}{c}\mathrm{New}_{\mathrm{t}} \\
\mathrm{Ns}^{2} / \mathrm{m}^{8}\end{array}$ & $\begin{array}{c}\text { New Q } \\
\mathrm{m}^{3} / \mathrm{s}\end{array}$ & $\begin{array}{c}\text { Difference } \\
\%\end{array}$ \\
\hline Fully closed & 2.05 & 32.73 & 2.23 & -8.0 \\
1 board off & 2.53 & 17.49 & 2.67 & -5.2 \\
2 boards off & 3.02 & 10.80 & 2.98 & 1.1 \\
3 boards off & 3.33 & 7.27 & 3.17 & 5.1 \\
4 boards off & 3.35 & 5.18 & 3.35 & 0.0 \\
5 boards off & 3.46 & 3.84 & 3.50 & -1.1 \\
6 boards off & 3.62 & 2.93 & 3.51 & 3.1 \\
7 boards off & 3.75 & 2.28 & 3.63 & 3.4 \\
8 boards off & 3.82 & 1.81 & 3.72 & 2.7 \\
9 boards off & 3.85 & 1.45 & 3.81 & 1.0 \\
10 boards off & 3.86 & 1.17 & 4.03 & -4.3 \\
11 boards off & 4.00 & 0.95 & 3.97 & 0.6 \\
12 boards off & 3.90 & 0.78 & 3.93 & -0.8 \\
13 boards off & 3.85 & 0.63 & 3.97 & -3.1 \\
14 boards off & 3.89 & 0.52 & 3.68 & 5.7 \\
\hline
\end{tabular}

It can be seen from both the table and the graph that the difference is at all times less than 10 percent which is well within practical underground meas- urement tolerance and therefore this new equation is sufficiently reliable to be employed for further analysis.

The relationship between the regulator opening area and total resistance can be derived as shown in Figure 6. Based on this, pressure and airflow quantity relationships (of the form $\mathrm{P}=\mathrm{RQ}^{2}$ ) can be calculated from mine regulator impedance characteristic curves. These can be drawn for different mine configurations as shown in Figure 7. The three curves shown illustrate relationships from Table 3 for one, three and five boards removed from the regulator.

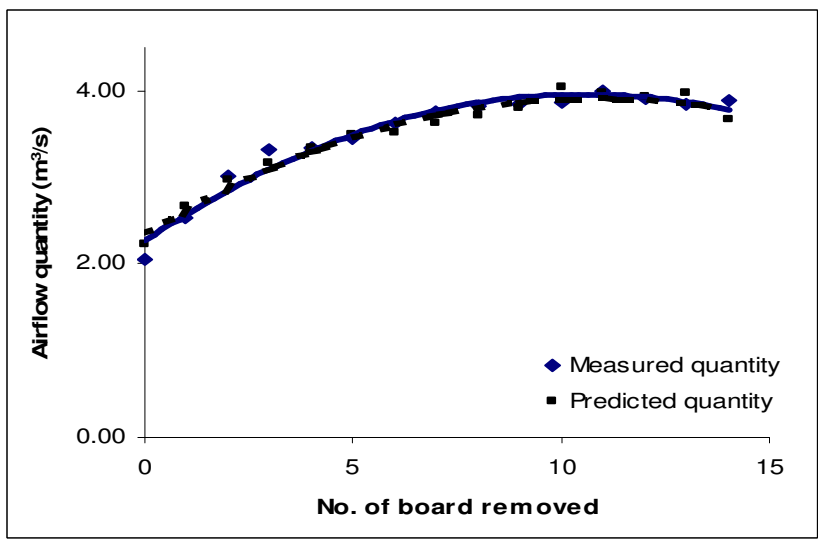

Figure 5. Comparison between measured and new predicted quantity.

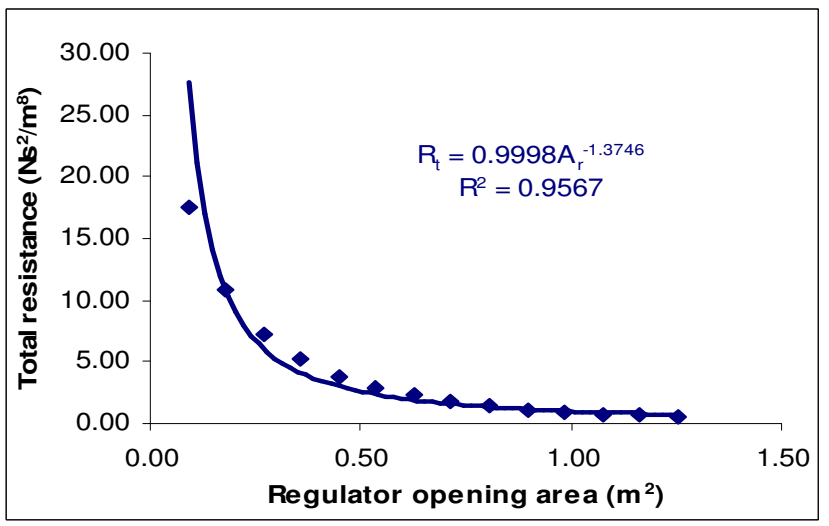

Figure 6. Relationship between new total resistance and regulator opening area.

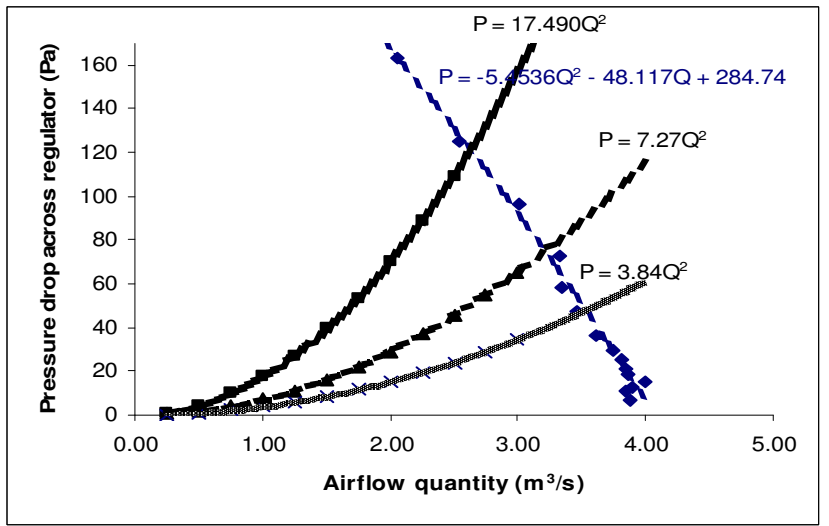

Figure 7. UQEM regulator characteristic curves. 
An investigation was conducted to check on whether the test method maintained accuracy with less measurement data. It was found that with half the number of measurements taken (removing two boards at one time instead of one board) differences remained mostly less than 10 percent and the method was still considered reliable.

\section{UQEM REAL TIME MINE VENTILATION SYSTEM}

The aim of this mine ventilation research was to develop a computerised monitoring system to provide immediate or real time simulated information on each branch within an underground ventilation network. The system measures airflow or air pressure changes in selected ventilation branches and simulate flows through all other branches. This new approach to ventilation provides improved understanding of airflows through all mine sections. The popular ventilation simulation modeling program Ventsim has been used as a simulation engine within the system. This software has been altered to accept real time information generated by underground mine ventilation monitoring sensors, undertake network simulations and interpret key system data and operational changes. Once the simulation program has updated readings it can remodel the whole mine system, report the flows in all branches and compare individual branch readings with expected values.

The UQEM was used to test the integration of a telemetry system into the Ventsim network analysis environment. An isometric plan of the UQEM is shown in Figure 8. The mine airflow monitoring system included consisted of one El-Equip "Flosonic" and two vortex shedding Sieger BA5 air velocity sensors. The FloSonic air velocity sensor is an ultrasonic anemometer measuring the average air velocity value across a drift with very good accuracy

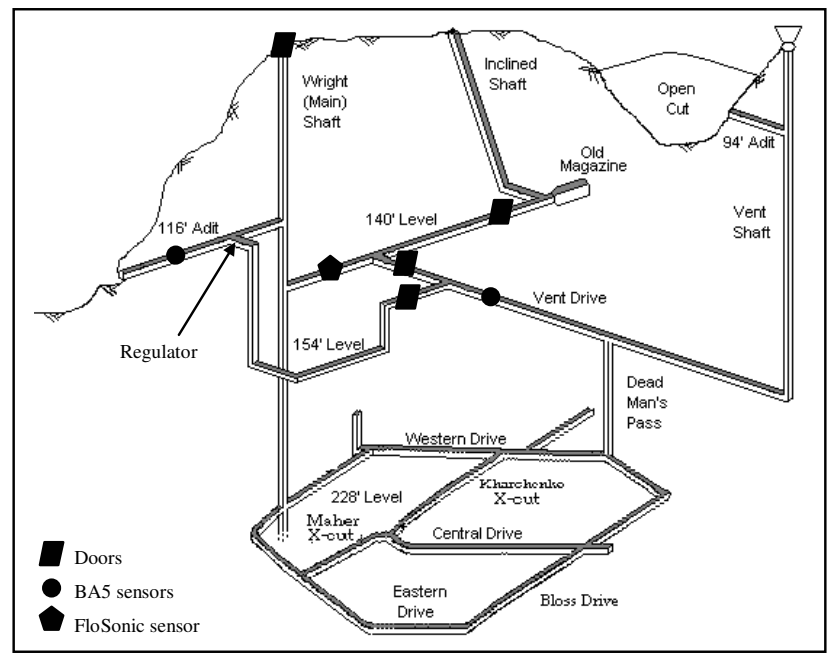

Figure 8. Plan of UQEM showing location of doors and sensors.
(Casten et al, 1995 \& McDaniel et al, 1999). The ini tial aim of this testing was to use the system to monitor changing ventilation conditions, to establish airflow characteristics within the UQEM and to observe the resimulated network results.

Achievement of the main research aim was facilitated with the development of a real time solution requiring data communication links between the various system components. These components included the UQEM telemetry monitoring system, the telemetry control software, the developed data manipulation applications, a File Transfer Protocol (FTP) application and a modified real time version of Ventsim. Details of the integration of the UQEM real time ventilation monitoring system including Ventsim modification have been described by Gillies et al (2000).

\section{TRIALS OF THE UQEM SYSTEM}

The performance of the modified airflow real time ventilation monitoring system at UQEM was evaluated. Parameters examined in this trial were:

1. The ability of the system to detect changes in the mine ventilation system.

2. The accuracy of airflow quantity prediction in unmonitored branches within the mine ventilation network based on the number of sensors linked to the system.

3. Constraints limiting performance of the system.

\subsection{Test results}

Four trial scenarios were implemented in the evaluation tests:

I. The inclined shaft door was open, and the regulator in 116' level set on fully open.

II. The inclined shaft door was open, and the regulator was set $1 / 5$ open with 12 boards on.

III. The inclined shaft door was open, and the regulator set on fully closed.

IV. The inclined shaft door was closed, and the regulator was set on fully open.

For the purpose of the tests the main shaft and the double doors on the 140' level were closed and the door on the 154' level was removed to increase airflow through the 116' adit and inclined shaft. During the tests field measurements using a calibrated vane anemometer and pressure transducer were conducted at the 116' adit, 116' regulator, inclined shaft and ventilation drive on the 140' level past the Dead Man's Pass as shown in Figure 9 and referenced as Station 26-11. Results of these measurements were then compared with predicted values generated from the real time Ventsim models. The aim here was to evaluate the accuracy of airflow quantity prediction in unmonitored branches. The real time Ventsim models were run with one to three real time airflow 
sensors link to the software and reporting to the Ventsim program as "Fixed Quantity" branch quantity values. Theoretically more sensors linked to the system should give greater accuracy as real measurements from a greater mine geographic area and representing more realistic conditions of the mine are available.

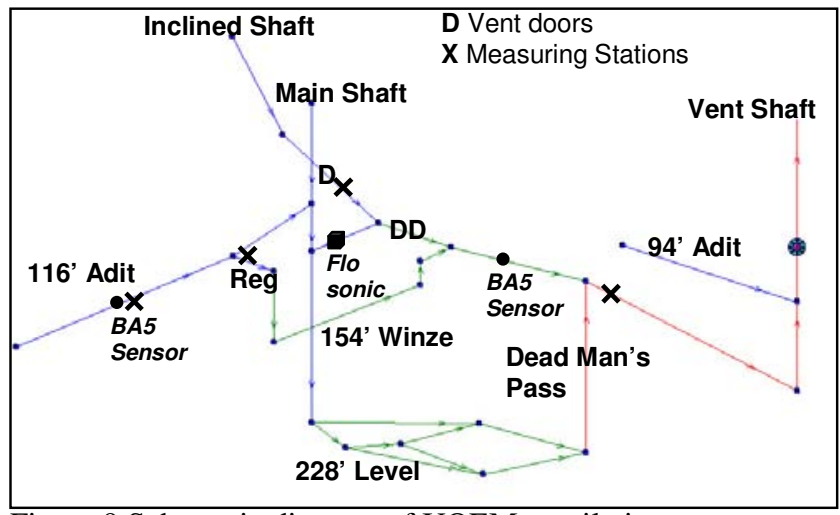

Figure 9 Schematic diagram of UQEM ventilation system.

Due to the electrical sensing problems encountered with the BA5 vortex-shedding sensor installed in 116 Adit, it was decided that the outputs from that sensor would not be included in the tests. A summary of the results is shown in Table 4.

It can be seen that the UQEM real time Ventsim monitoring system performs with reasonable accuracy, although some differences in quantities were larger than 10 percent as shown in the table. For example, the quantities through inclined shaft when the door connected to inclined shaft in 140' level was closed. However, this is acceptable, since the quantities predicted (ranging around $0.8-0.9 \mathrm{~m}^{3} / \mathrm{s}$ ) and measured (around $0.6 \mathrm{~m}^{3} / \mathrm{s}$ ) in these cases were low.

Table 4 Summary of trial results at UQEM.

\begin{tabular}{|c|c|c|c|c|c|c|}
\hline \multirow[t]{2}{*}{ Scenario } & \multicolumn{6}{|c|}{ Quantity $\left(\mathrm{m}^{3} / \mathrm{s}\right)$} \\
\hline & Predicted & Measured & Diff (\%) & Predicted & Measured & Diff (\%) \\
\hline \multicolumn{7}{|c|}{ One sensor linkage } \\
\hline & \multicolumn{3}{|c|}{ Regulator } & \multicolumn{3}{|c|}{$116^{\prime}$ adit } \\
\hline I & 3.1 & 2.8 & -9.7 & 3.9 & 4.1 & 5.0 \\
\hline II & 2.2 & 2.1 & -2.9 & 3.8 & 3.8 & -0.4 \\
\hline III & 1.7 & 1.3 & -22.0 & 3.7 & 3.7 & 0.2 \\
\hline \multirow[t]{2}{*}{ IV } & 3 & 2.8 & -6.7 & 4.9 & 5.3 & 8.4 \\
\hline & \multicolumn{3}{|c|}{ Inclined shaft } & \multicolumn{3}{|c|}{ Station $26-11$} \\
\hline I & 2.8 & 2.8 & -0.4 & 9.1 & 9.1 & -0.1 \\
\hline II & 2.7 & 2.8 & 4.3 & 8.9 & 9.0 & 1.2 \\
\hline III & 2.7 & 2.8 & 2.7 & 8.8 & 8.7 & -0.9 \\
\hline IV & 0.9 & 0.6 & -38.7 & 8.8 & 9.0 & 1.9 \\
\hline \multicolumn{7}{|c|}{ Two sensors linkage } \\
\hline & \multicolumn{3}{|c|}{ Regulator } & \multicolumn{3}{|c|}{$116^{\prime}$ adit } \\
\hline I & 3.1 & 2.8 & -9.7 & 3.9 & 4.1 & 5.0 \\
\hline II & 2.2 & 2.1 & -2.9 & 3.8 & 3.8 & -0.4 \\
\hline III & 1.7 & 1.3 & -22.0 & 3.7 & 3.7 & 0.2 \\
\hline IV & 2.8 & 2.8 & 0.0 & 4.9 & 5.3 & 8.4 \\
\hline & \multicolumn{3}{|c|}{ Inclined shaft } & \multicolumn{3}{|c|}{ Station $26-11$} \\
\hline I & 2.8 & 2.8 & -0.4 & 9.1 & 9.1 & -0.1 \\
\hline II & 2.7 & 2.8 & 4.3 & 8.9 & 9.0 & 1.2 \\
\hline III & 2.7 & 2.8 & 2.7 & 8.8 & 8.7 & -0.9 \\
\hline IV & 0.8 & 0.6 & -31.0 & 8.8 & 9.0 & 1.9 \\
\hline
\end{tabular}

Results in Table 4 indicate that the system can predict changes within the mine ventilation system. The system predicted decrease in the regulator quantity as the regulator opening decreased. It also predicted decrease in quantity through the inclined shaft as the door was closed.

Within these tests no significant difference between the accuracy of one and two sensors linked to the system was observed. However, it cannot be concluded that this would be the case in a large operating mine since the location of the sensors will also have an important influence.

\subsection{Constraints of the system}

As described before, one aim of these tests was to identify constraints that might limit performance of the system. One major point of interest is the delay time or transient period between the instant of a change and when the system detects the change. The results of some changes are summarized in Table 5 .

The transient period in UQEM is short and therefore is not of great significance in interpreting the network system. However, in large-scale mines, the period can be up to 10 minutes.

Table 5 Summary of the transition time observed.

\begin{tabular}{|l|c|}
\hline \multicolumn{1}{|c|}{ Changes } & Time \\
\hline Regulator fully open to 12 boards & 70 seconds \\
Regulator 12 boards to fully closed & 36 seconds \\
Regulator fully closed to fully open & 84 seconds \\
Inclined shaft door open to closed & 72 seconds \\
Inclined shaft door closed to open & 75 seconds \\
\hline
\end{tabular}

What this means is that reliance cannot be placed completely on "real time" airflow readings being instantaneously correct as reported for all branches within a mine ventilation simulated network. There is nothing that can be done to eliminate this characteristic as it is representative of the nature of airflow within underground mines. A change which leads to a hazardous condition may go unreported for time interval of this transient period. Of course changes in mine ventilation systems measured manually are rarely immediately picked up but the limitations of an automatically reporting real time system should be recognized.

\subsection{Updating of Ventilation Network Simulation Models}

From these trial results there is confidence that the computerized monitoring system is capable of providing immediate or real time simulated information on each branch within an underground ventilation network, is able to detect changes in the ventilation system monitored and is also able to predict flow within the unmonitored braches with reasonable accuracy. 
The system has also been seen to have the ability to update the mine ventilation network model and keep this mine planning tool current. Mine ventilation models are normally static simulation models that are accurate when calibrated after a mine ventilation survey. Even with care in frequent updating models will tend to lose accuracy. The real time approach allows the model to be seen as a dynamic entity that can be tested for its accuracy at any time without the effort of undertaking a full ventilation survey.

In a typical mine operation, any ventilation change must be authorized before the change is made. Alternative options are evaluated through computer network simulation or manual calculations in the planning phases. Once the " best achievable" alternative is determined, authorization is gained and necessary adjustments to some of the system regulators made. Underground ventilation measurements may at some time be conducted to verify the effects of the change.

A real time ventilation monitoring system can reduce or eliminate the need for numerous underground measurements necessary to verify the effects of ventilation system changes. The real time sensors installed in strategic locations will pick up airflow changes and subsequently make prediction of quantities in all other airways. However, the real time Ventsim models after detection of the changes should be modified to form an updated system model representative of the changes that has taken place and ready for future planning exercises.

The data collected during the trial was reexamined as an exercise to demonstrate the important and necessity of modification of the real time simulation models after the imposition of changes, The first three scenarios used the regulator settings: fully open, 1/5 open and fully closed were reexamined with two real time airflow sensor link underground. Table 6 summarizes the results of this exercise.

The second column in Table 6 shows the predicted air quantities at various UQEM locations based on the outputs from the original Ventsim model without activated real time sensors inputs. The values were obtained by varying the regulator resistances using values obtained from the drop board regulator tests undertaken at UQEM as shown in Table 2 and then running the network simulation for prediction in the "planning phase". These values serve as guidance for what air quantities will be expected if regulator settings have been changed.

Once these values are obtained, mine ventilation personnel can make preliminary evaluations folllowed by regulator adjustments to see what air quantity flows in key branches. As mentioned, underground ventilation measurements are conducted to verify the effects of the change made.
Table 6 Comparisons of quantity and pressure predictions and underground measurements

\begin{tabular}{|c|c|c|c|c|c|c|c|}
\hline Scenario & \begin{tabular}{|c|} 
Predicted \\
original \\
Ventsim $\mathrm{R}$ \\
changed
\end{tabular} & $\begin{array}{c}\% \\
\text { error } \\
\text { with } \\
\text { mea- } \\
\text { sured }\end{array}$ & \begin{tabular}{|c|} 
Predicted \\
realtime \\
Ventsim R \\
un- \\
changed
\end{tabular} & \begin{tabular}{|c|}
$\%$ \\
error \\
with \\
mea- \\
sured
\end{tabular} & $\begin{array}{c}\text { Predicted } \\
\text { realtime } \\
\text { Ventsim } \mathrm{R} \\
\text { changed }\end{array}$ & \begin{tabular}{|c|}
$\%$ \\
error \\
with \\
mea- \\
sured
\end{tabular} & $\begin{array}{l}\text { Mea- } \\
\text { sured }\end{array}$ \\
\hline & \multicolumn{7}{|c|}{ Regulator Quantity $\left(\mathrm{m}^{3} / \mathrm{s}\right)$} \\
\hline $\bar{T}$ & 3.1 & 10.7 & 3.1 & 10.7 & 3.0 & 7.1 & 2.80 \\
\hline II & 2.5 & 17.1 & 2.2 & 3.0 & 2.1 & -1.7 & 2.14 \\
\hline \multirow[t]{2}{*}{ III } & 1.6 & 21.5 & 1.8 & 36.7 & 1.5 & 13.9 & 1.32 \\
\hline & \multicolumn{7}{|c|}{ Regulator Pressure $(\mathrm{Pa})$} \\
\hline $\mathrm{I}$ & 4.9 & 25.0 & 4.4 & 12.2 & 4.4 & 12.2 & 3.9 \\
\hline II & 45.2 & 50.7 & 2.4 & -92.0 & 28.7 & -4.3 & 30.0 \\
\hline \multirow[t]{2}{*}{ III } & 98.4 & 44.7 & 1.6 & \begin{tabular}{|l|}
-97.6 \\
\end{tabular} & 91.7 & 34.9 & 68.0 \\
\hline & \multicolumn{7}{|c|}{ 1116' adit Quantity $\left(\mathrm{m}^{3} / \mathrm{s}\right)$} \\
\hline $\bar{T}$ & 3.9 & -4.7 & 3.9 & -4.7 & 3.8 & -7.2 & 4.09 \\
\hline II & 3.8 & 0.4 & 3.8 & 0.4 & 3.7 & -2.2 & 3.79 \\
\hline \multirow[t]{2}{*}{ III } & 3.7 & -0.2 & 3.8 & 2.5 & 3.6 & -2.9 & 3.71 \\
\hline & \multicolumn{7}{|c|}{ Inclined Shaft Quantity $\left(\mathrm{m}^{3} / \mathrm{s}\right)$} \\
\hline I & 2.8 & 0.4 & 2.8 & 0.4 & 2.9 & 4.0 & 2.79 \\
\hline II & 2.7 & -4.1 & 2.7 & -4.1 & 2.8 & -0.5 & 2.82 \\
\hline \multirow[t]{2}{*}{ III } & 2.8 & 0.9 & 2.7 & -2.7 & 2.9 & 4.5 & 2.77 \\
\hline & \multicolumn{7}{|c|}{ Station 26-11 Quantity $\left(\mathrm{m}^{3} / \mathrm{s}\right)$} \\
\hline $\mathrm{I}$ & 9.1 & 0.1 & 9.1 & 0.1 & 9.1 & 0.1 & 9.09 \\
\hline II & 9.0 & -0.1 & 8.9 & -1.2 & 8.9 & -1.2 & 9.01 \\
\hline III & 8.8 & 0.9 & 8.8 & 0.9 & 8.8 & 0.9 & 8.72 \\
\hline
\end{tabular}

The fourth column corresponds to the predicted values from real time Ventsim simulation models with inputs from real time airflow sensors as fixed quantities. These values are those that been displayed on the real time UQEM ventilation monitoring and simulation system during the trial. They were predicted without changing the resistance values of regulator in the Ventsim model. These air quantities compared well with the actual measured values as indicated in the eighth column of the table.

Based on the air quantities obtained from the real time UQEM monitoring and simulation system, it seems that it is not necessary to make adjustment to the regulator resistance value in the real time Ventsim model, as \% error in the three locations (as shown in the fifth column of the table) is no more than 5 percent. However, when comparing the predicted pressure drops across regulators for the three scenarios, significant need for adjustment was found. Without changing the resistance values of regulators in the computer model, pressure drops predicted by the model were far off from the actual pressure drops measured across the regulator.

Therefore, it is necessary to change the resistance values of the regulator in the real time Ventsim model after the detection of the changes in the ventilation system. The sixth column in Table 6 represents the outputs from the real time model after updating the Ventsim model for changes made in the setting of the drop board regulator during the trial. These values when compared with the measured values are more accurate than values shown in the second and fourth columns. 
It should be noted that the real time model is not fully useful then without frequent updating to reflect changes in the mine from ongoing mining activities. From the monitoring system it should also be possible to monitor historical trends and identify patterns corresponding to mining cycles. From this it should be possible to flag situations where it has been established that subsequent to a significant mining step the model will require this significant update. Ventilation systems change gradually over time but also in step changes when a cut through or cross cut is formed or a new panel opened up.

It is concluded that while the real time ventilation monitoring and simulation system is able to detect change in a mine ventilation system and make airflow prediction with reasonable accuracy, it is still necessary to modify the real time simulation model following and because of changes to gain better accuracy. It is noted that when solely relying on the use of airflow sensors based on the "Fixed Quantity" simulation principle, it is necessary to check the pressure drops across the regulators in the system to determine whether to modify the real time model or not. This can be done through the use of differential pressure sensors. The main advantage is this approach allows continuous updating of the Ventsim model and checking of its accuracy as the mine ventilation system is extended and evolves.

\section{CONCLUSIONS}

Efforts to characterize or mathematically model a number of operating mine regulators have been described. Underground measurements have indicated that theoretical calculations to predict airflow quantity through practical mine regulators based on measured pressure drop are inadequate. The theoretical approaches are limited as they are based on prediction of fluid flow through a circular orifice in the middle of a plate whereas most mine regulators have a rectangular non-symmetrically positioned orifice. Also, most importantly, there is air leakage through the regulator bulkhead frame and gaps that increase actual quantity compared to that predicted.

The way to overcome this difference is to quantify the resistance of the leakage path based on regulator opening area and then recalculates the total resistance of the regulators. The relationship between leakage path resistance and regulator opening area varies, but the resistance should increase along with an increase in opening area. Based on measured pressure difference, the airflow quantity can be predicted accurately using the basic square law. It requires field measurement to quantify the leakage path resistance of each regulator, since each regulator has its own leakage characteristic (size and number of gaps, etc.). This is a tedious work, since the regulators can be set with many opening areas.
However, it was found that with limited measurement data, prediction results are still accurate within acceptable tolerance appropriate to understanding mine airflows.

The aim of the study was to gain greater understanding of a computerized monitoring system to provide immediate or real time simulated information in each branch of an underground ventilation network. The system measures airflow in selected ventilation branches and simulates flows through all other branches. An investigation was undertaken as to whether the UQEM Real Time Airflow Monitoring system can detect changes within the mine ventilation system, examine accuracy of the system and identify constraints that will limit performance of the system. As a result of trials, it was demonstrated that the system was able to detect changes occurring within the mine ventilation system and was also able to predict the changes accurately. Limitations caused by transient period delays have been examined. Updating of simulation models from use of real time data has also been discussed. It is envisaged in the future that the ventilation model would be an integral part of a real time mine wide planning, monitoring and control software platform from which the model would be updated in real time.

\section{ACKNOWLEDGEMENT}

The support of the University of Queensland and a number of operations within the Australian mining industry in funding this study are acknowledged.

\section{REFERENCES}

Burrows, J, Hemp, R., Holding, W. \& Stroh, R.M., 1989. Environmental Engineering in South African Mines, 2nd edition, pp 66-70 Mine Vent. Soc. South Africa, Johannesburg.

Casten, T., Mousset-Jones, P., and Calizaya, F., 1995. Ultrasonic Anemometry in Underground Excavations, Proc 7th US Mine Vent Sym, Lexington, Kentucky, 1995, pp 429434. Ed A.M. Wala. SME, Littleton, Colorado, USA.

Gillies, A.D.S., Mayes, T.I., Wu, H.W., Kizil, M. \& Wang, N., 2000. The Development of a Real Time Airflow Monitoring and Control System, Proc 1st Mine Envirn and Vent Sym, Dhanbad, India, 2000, pp 255-264. Ed D.C. Panigrahi. A.A. Balkema, Rotterdam.

Kingery, D.S., 1960. Introduction to Mine Ventilating Principles and Practices, US Bureau of Mines Bul 589, pp 89 (US Bureau of Mines, Washington DC).

Le Roux, W.L., 1979. Mine Ventilation Notes for Beginners, 3rd edition, pp 131-133 Mine Vent. Soc. South Africa, Johannesburg.

McDaniel, K., Duckworth, I.J., and Prosser, B.S., 1999. Evaluation of Different Airflow Sensors at the WIPP Facility, Proceedings of 8th US Mine Vent Sym, Rolla, Missouri, 1999, pp 519-525. Ed J.C. Tien. SME, Littleton, Colorado, USA.

McElroy, G.E., 1935. Engineering Factors in Ventilating Metal Mines, US Bureau of Mines Bull 385, pp 55-68 (US Bureau of Mines, Washington DC). 